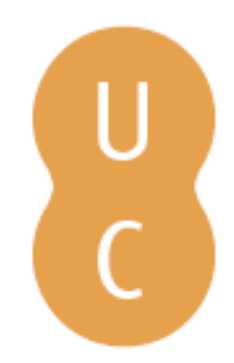

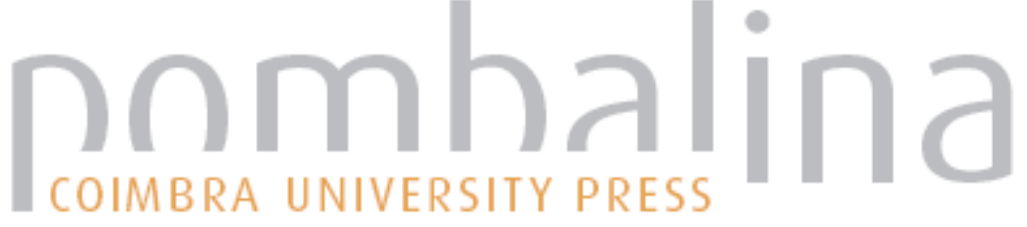

\section{¿Cómo salir de los valores rasos de la educación postmoderna?}

\author{
Autor(es): $\quad$ Fullat Genís, Octavi
}

Publicado por: Imprensa da Universidade de Coimbra

URL

persistente: URI:http://hdl.handle.net/10316.2/32414

DOI: $\quad$ DOI:http://dx.doi.org/10.14195/978-989-26-0767-2_2

Accessed : $\quad$ 26-Apr-2023 13:47:49

A navegação consulta e descarregamento dos títulos inseridos nas Bibliotecas Digitais UC Digitalis, UC Pombalina e UC Impactum, pressupõem a aceitação plena e sem reservas dos Termos e Condições de Uso destas Bibliotecas Digitais, disponíveis em https://digitalis.uc.pt/pt-pt/termos.

Conforme exposto nos referidos Termos e Condições de Uso, o descarregamento de títulos de acesso restrito requer uma licença válida de autorização devendo o utilizador aceder ao(s) documento(s) a partir de um endereço de IP da instituição detentora da supramencionada licença.

Ao utilizador é apenas permitido o descarregamento para uso pessoal, pelo que o emprego do(s) título(s) descarregado(s) para outro fim, designadamente comercial, carece de autorização do respetivo autor ou editor da obra.

Na medida em que todas as obras da UC Digitalis se encontram protegidas pelo Código do Direito de Autor e Direitos Conexos e demais legislação aplicável, toda a cópia, parcial ou total, deste documento, nos casos em que é legalmente admitida, deverá conter ou fazer-se acompanhar por este aviso.

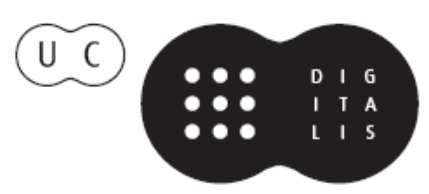




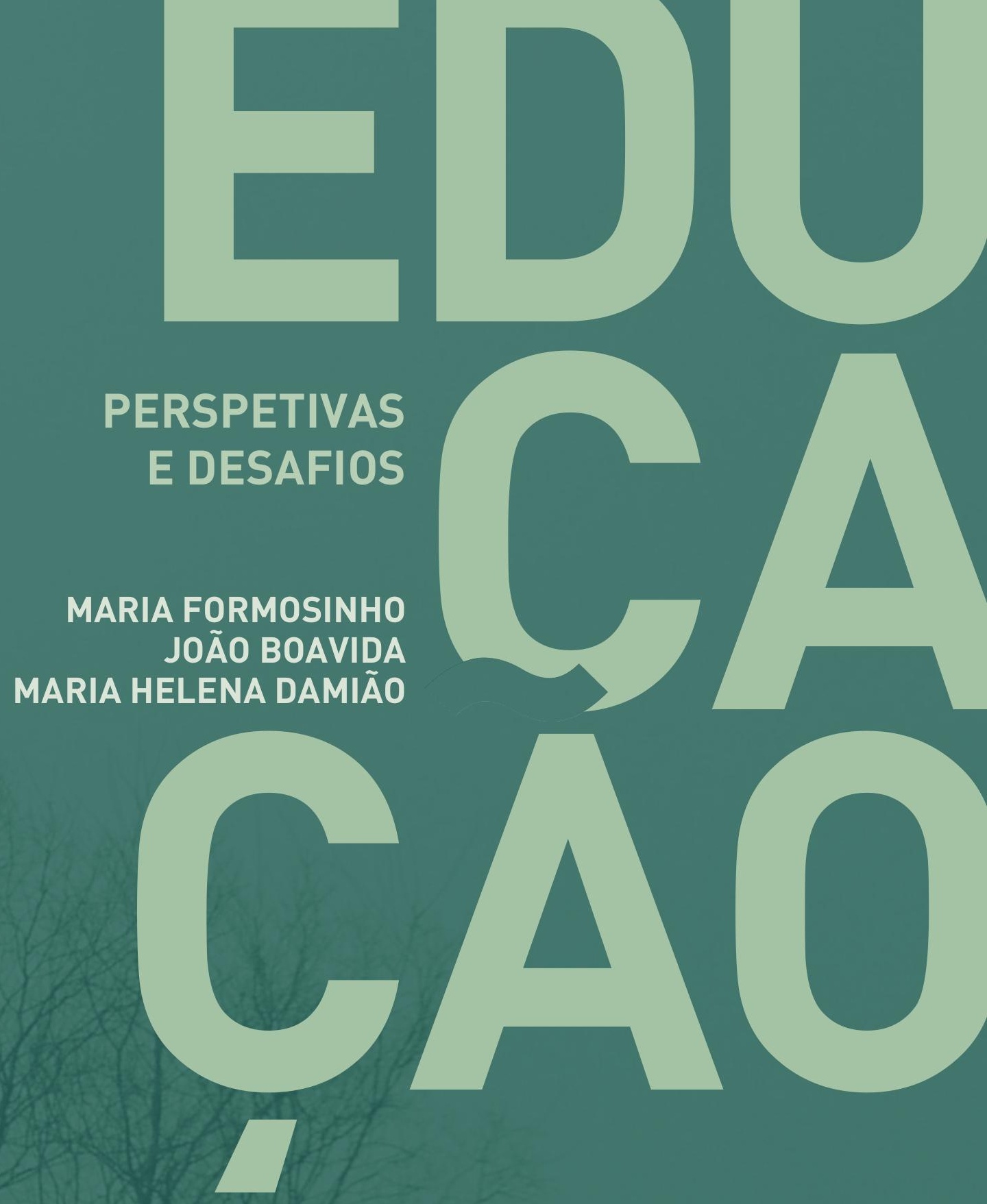

IMPRENSA DA

UNIVERSIDADE

DE COIMBRA

COIMBRA

UNIVERSITY

PRESS 


\section{Octavi Fullat Genís}

Universitat Autónoma de Barcelona

\section{¿CÓ́MO SALIR DE LOS VALORES RASOS DE LA EDUCACIÓN POSTMODER NA?}

\section{Introducción}

Estamos instalados en la educación postmoderna y en los valores efímeros que la vertebran. No insisto sobre el particular. Mi enfoque se coloca en el plano de la legitimación de tal modelo axiológico-educativo. Estimo que la producción de Heidegger aporta el discurso más potente en vistas a hacer plausible la axiología débil y efímera que especifica a la pedagogía postmoderna, a las pedagogías líquidas. Lo postmoderno nació en 1900 con el óbito de Nietzsche; después no ha hecho más que crecer sin Absoluto alguno.

En el seno de la Postmodernidad los valores carecen de relieve; son, pues, irrelevantes. Variopintos y fugaces. Este dato desmarca ya al valor ético con respecto a sus orígenes. En Platón la areté - "excelencia o mérito" - convierte al ser humano que la posee en agathos - "bueno y valioso". El axios griego - derivado del verbo axioo, "estimado justo o digno" - es lo merecedor de aprecio. Tanto areté, que es costumbre traducir con la palabra virtud, como axios, que se estila verter al castellano con el vocablo valor, señalan a realidades consistentes y estables, en modo alguno volanderas e inconstantes. La Postmodernidad ha roto con los hontanares de Occidente si prescindimos de los sofistas, los cuales prefiguraron ya dicha fractura.

Tanto los enunciados prescriptivos o directivos - e.g. "Está prohibido torturar" - como los evaluativos - e.g. "Es preferible ayudar al necesitado que abandonarlo a su suerte" - son enunciados que presuponen al valor universal griego. Sobre el estudio lógico-lingüístico 
de dichos enunciados véase Wiggins (1991). Verdad es que no hemos avanzado mucho con respecto al planteamiento que Platón formula en el Euthyphron e Peri hosiou (10a-11b) cuando se pregunta si un acto es piadoso porque agrada a los dioses o bien agrada a los dioses porque dicho acto es, él mismo, piadoso. Con todo acabó triunfando hasta el Renacimiento la solidez del valor. Hume en el libro A Treatise of Human Nature (1740) al distinguir entre fact y value, entre is y ought, introduce una frontera notable entre lo normativo y lo descriptivo. La tradición griega, de esta suerte, se quiebra. Moore en Principia Ethica (1903) insiste sobre este mismo extremo; el término bien no puede definirse con enunciados factuales o empíricos, pues al fin y al cabo ¿cómo se sabe que aquello que sirve para definir empíricamente al bien es, ello, un bien? Preludios de la ética postmoderna. Lo valorativo caminará sin la fuerza de la ciencia, si se entiende a ésta tal como la definió Galileo en Discorsi e dimostrazioni matematiche intorno a due nuove scienze (1638), redefinición que llevó a cabo gracias a su práctica científica. Si lo respetable es aquello que se ha probado experimentalmente, la ética pierde autoridad e importancia delante, cuando menos, del científico.

\section{Modelo antropo-educativo de la postmodernidad}

Deleuze con su obra Nietzsche et la philosophie (1962) se acredita como el pensador postmoderno más sólido después de Heidegger. Cuando Nietzsche sostiene la voluntad de poder y el eterno retorno afirma la crítica tanto de la moral como de la religión, crítica que la filosofía no llevó hasta el final ni con los sofistas ni con Hegel ni tampoco con Marx. Nietzsche, en cambio, dice Deleuze, substituye la autoridad de la razón con el poder constituyente del deseo. Nietzsche ha superado no sólo la moral, mas igualmente ha vencido a la tradición racionalista. La metafísica de la identidad queda, así, abandonada.

Ya en el terreno de la pedagogía postmoderna la producción escrita de Niklas Luhmann, fallecido en 1999, resulta significativa. El yo y el tú del proceso educativo son sobreros quedando la individualidad reducida 
a un subsistema de sistemas complejos. Detrás de esta doctrina están Maturana y Varela aunque el planteamiento biológico de éstos se trueca en estructuras sociales en el caso de Luhmann. En el apéndice a la obra El sistema educativo escribe:

Se hacen obsoletos la idea de un bien por encima de los demás y el concepto de lo adecuado con carácter general e inmutable (...).

No hay cumbre ni centro; sólo existe un conjunto operativo con un código funcionalmente específico (...).

Los niños, los escolares, son máquinas (...), aunque, esto sí, con mayor inseguridad en su relación con el programa. (Luhnmann, 1993, p. 402)

El modelo antropológico-educativo de la Postmodernidad descansa sobre una tecnología despojada de sujeto humano. El saber ni lo produce ni tampoco lo comunica el individuo, sino el sistema social y sus subsistemas. Mi hipótesis apunta a que el pensamiento de Heidegger constituye el cuerpo de doctrina más vigoroso para dar cuenta de la insubstantividad de los valores planos con los que vive la educación postmoderna. No resulta cómodo hacerse con el discurso heideggeriano pero no dudo que su lectura de Nietzsche (Heidegger, 1961), que logra sistematizar la obra de éste - una verdadera Lebensphilosophie ("filosofía de la vida") -, es penetrante y a su vez permite hacerse cargo del resto de los escritos heideggerianos. Presento las líneas de pensamiento de Heidegger y a su vez al personaje. Se me antoja más estimulante y completo.

El siglo Xx ha visto como se rompía la idea misma de humanidad. Los individuos dejaban de pertenecer, todos, a la misma y única comunidad humana. Siempre ha existido la crueldad banal; la barbarie ha sido asunto generalizado en el proceso histórico y en la diversidad de geografías. Lo novedoso y sorprendente del siglo $\mathrm{xx}$ reside en que tanto para el nazismo como igualmente para el comunismo la violencia constituye un deber, una virtud y un método en vez, como sucedía otrora, de ser deleite, sadismo y placer. La brutalidad se ha mudado en competencia de un buen profesional. Nazismo y comunismo son voluntarismos que han decidido construir la historia por encima de las vidas individuales. 
El siglo $\mathrm{xx}$ ha sido, simultáneamente, tecnocientífico y bárbaro. El XIX había creído que la ciencia forzaría la barbarie a retroceder, pero no ha sido así. La extensión de los saberes ha ido acompañada del salvajismo más sereno. Televisión en colores y triunfo de los satélites se han codeado con torturas y campos de concentración refinados. Existencialismos y postmodernidades brotan en este humus. La duda y la perplejidad han ocupado el lugar de las certezas y de los dogmatismos. ¿Qué significan en tal coyuntura comprender al mundo y transformarlo? El nihilismo de la desesperación acecha. Los postmodernos no caen, empero, en él con confesar que no se da la salvación. Se inspiran en Nietzsche quien había esbozado otros derroteros menos trágicos. Así Rorty (1979, 1989) imbuido en la Teoría pragmática de la verdad, que desarrolló William James, se contenta con la esperanza en espacios racionales, siempre que no se deifique a tal proceder.

La metafísica, después de 2.400 años de dominio, acusa fatiga. Heidegger le echa en cara el que haya pretendido enseñorearse del ser en vez de colocarse a su escucha. El Principium reddendae rationis de Leibniz, gran exponente metafísico, sufre menoscabo en manos de Heidegger (Heidegger, 1957). Los postmodernos rechazan cualquier modalidad de fundacionalismo; buscar fundamentos últimos tanto del saber como de la realidad no es otra cosa que obstinarse en querer proseguir con seguridades ilusorias. Creer en la razón absoluta ha traído a Hitler, a Stalin, al complejo industrial-militar norteamericano... La Postmodernidad desconfía de cualquier poder - político, tecnológico, científico, religioso, artístico, económico, místico... - porque usurpa la autoridad de la razón. Lo mejor es declarar, a ésta, pordiosera y quebrada.

\section{Implicaciones del discurso heideggeriano}

Heidegger es el postmoderno fundamental; el resto a su lado es medianía. Husserl con la idea de intencionalidad rompió el espacio cerrado de la conciencia del yo, como asimismo logró colocar formas de predicados y verdades de predicados en la esfera prepredicativa de la intuición; sin 
embargo, Heidegger le acusa de no abordar al das Sein der Sachen - "Ser de las cosas" - puesto que lo hace coincidir con su "ser-consciente" Bewusst-sein - sin plantearse en qué consiste el ser de la conciencia, el de la intencionalidad y el sentido del Ser. Husserl no pudo superar la filosofía cartesiana del Ego cogito entendiendo al Ser como elemental presencia - Anwesenheit. Heidegger abandona la fenomenología trascendental de Husserl proponiendo una fenomenología hermenéutica. El Dasein - el Aquí-del-Ser o ser humano -, desprovisto de conciencia y de yo, es la "comprensión expresa del Ser" - Seinsverständnis. Quedaba destrozado de tal guisa el Sentido Universal y Absoluto de la Modernidad. En Heidegger el camino no une el punto de salida y el punto de llegada. El pensamiento no va tras del Ser; se limita a estar ya en él. No contamos con carretera, sino con Holzweg, con "sendero forestal", que progresa sin encaminarse a punto alguno. El Dasein - "ser ahí" - funda o fundamenta, pero en el sentido de hallarse comprometido con el abismo del "sin-fondo" - Abgründiger Grund (Heidegger, 1929). El fundamento último de todo ya no es fundamento absoluto, sino un abismarse en la nada de sostén. El Ser se interroga en el Dasein y se descubre como aventura para la muerte - temporalidad, pues, y finitud -, y en la muerte solamente amenaza la nada. Heidegger transita de la fenomenología trascendental, de Husserl, a la fenomenología hermenéutica. Abandona la interioridad del sujeto con su autoconciencia - el ego cogito - sosteniendo algo anterior y más originario - el Dasein -, que fundamenta tanto al sujeto como a su apercepción. Y ¿por qué tal cambio? porque el sentido del ser anda relacionado con el Da-sein - el "ahí-del-ser" - y no con el acto de conciencia de un yo. El Selbst - el sí mismo de un yo - viene determinado por la "pre-manifestación" del ser, la cual se da en el estar existiendo, temporalmente, del Dasein. Heidegger lleva a cabo una hermenéutica, pero no de un texto - en Dilthey la hermenéutica era epistemología -, sino del ser mismo; la hermenéutica se muda ahora en ontología. No interesa cómo sabemos, sino qué es el ser, el cual, por cierto, únicamente se revela comprendiéndose. El Dasein no es sujeto frente a un objeto, sino un ente en el seno del ser; es el lugar donde el ser se hace cuestión de sí mismo, lugar que es lenguaje. Y el ser, en el Dasein, se autocomprende 
como proyección constitutiva. La "interpretación" ontológica - Auslegung - consiste en el "desplegarse" - sich ausbilden - del ser. La autocomprensión del ser, antes que discurso, es "poder-ser", es proyecto. En Heidegger el fundamento de la metafísica no es otro que el tiempo, con lo cual el ser no supera a la temporalidad e "historialidad" - geschichtlich. El ser acaba en "acontecer" - Ereignis -, en sencillamente producirse - es gibt (que significa "hay" o, literalmente, "eso da"). El ser humano pertenece a un elemental acontecer (Heidegger, 1969). La historialidad del Dasein, la finitud de éste - que constituye la revelación del ser -, se traduce en "ser-para-la-muerte" (Heidegger, 1927).

\section{El vórtice del compromiso político de la filosofía}

El hecho de que Heidegger se adhiriera al Partido Nazi y admirara a Hitler ha permitido plantear la pregunta sobre la relación entre sus convicciones políticas y sus escritos filosóficos. Ni la respuesta negativa ni tampoco la positiva sobre este particular pueden probarse objetivamente. Se trata de interpretaciones forzadas en ambos casos. Lo más cauto es sostener los hechos según los cuales Heidegger se hechizó con el nazismo alemán, y en especial con la figura de Adolf Hitler, y asimismo constatar las ideas filosóficas vertidas en sus libros mayúsculos. Interrelacionar ambos extremos resulta sin duda efectista pero no supera el plano de la especulación subjetiva. El libro de Víctor Farias Heidegger y el nazismo (1989) trajo muy pocas novedades historiográficas. El número de Temps modernes, de 1946, y el trabajo de Jean-Michel Palmier los Écrits politiques de Heidegger (1968) habían ya sacado a la luz los hechos. Yo no atino a descubrir una afinidad clara entre el pensamiento heideggeriano y los fundamentos del nazismo. Tal vez un par de cartas de la época en que fue Rector de la Universidad de Freiburg utilizan un lenguaje antisemita, pero esto queda contrarrestado por el hecho de no haber llevado sus hijos a las Hitlerjungen y de oponerse a que en su universidad se colocara el letrero de los S.S. reclamando la expulsión de los judíos. Por lo menos quedaba algo distante del nazismo. Y ¿por 
qué, concluido el conflicto bélico, guardó silencio acerca de su simpatía por Hitler? ¿por qué no renegó de aquel pasado suyo? Quizás no atinara en cómo hacerlo. Con todo, el 8 de abril de 1950 escribe una carta a Jaspers en la cual se expresa así: "Los hechos que traigo no disculpan de nada; únicamente hacen ver como a medida que se descubría el mal crecía en mí la vergüenza de haber, un día, contribuido en el desastre directa o indirectamente" (Jaspers, 1978, p. 97).

El discurso heideggeriano da vueltas en torno a la diferencia imperceptible pero absoluta que separa el Ser y el ente. No hay Ser sin entes como tampoco pueden darse los entes sin el Ser. La dificultad no se halla en el ámbito de los entes puesto que dicho ámbito es el mundo al cual pertenecemos. El caballo es un ente y Dios - si lo hay - es también un ente. El problema salta cuando se quiere averiguar en qué, el Ser del ente, se distingue del ente. Según Heidegger el Ser no es ni materia, ni espíritu, y nada puede afirmarse de él ya que carece de atributos. El logos, la razón, fracasa en tal empeño. En Sein und Zeit se lee: "El concepto de Ser resulta indefinible... El Ser no puede concebirse como un ente (...). De él no pueden predicarse entes (...). El Ser de los entes no es, él mismo, un ente (...)" (Heidegger, 1927/1963, p. 4, 6 y 38).

¿En qué consiste, entonces, el Ser? Una respuesta escueta la proporciona en ¿Qué es Metafísica? "El Ser es lo simplemente otro a todo ente; es decir, es nada" (Heidegger, 1929, p. 7).

El Ser configura una dimensión que se aguanta más allá de cualquier determinación óntica. El Ser no es ni papel, ni rosa, ni jilguero, ni ser humano, ni ángel, ni Dios, ni tampoco número. Estas cosas son, todas, entes. La "nada" - Nichts - pertenece al Ser en cuanto que éste es nada de ente. En Introducción a la Metafísica - Einführung in die Metaphysik - se expresa así: "El Ser por el cual nos preocupamos queda muy cerca de la nada, aunque evidentemente protestaríamos si alguien afirmara que el ente no es" (Heidegger, 1953, p. 87).

¿Por ventura podría sostenerse que sólo hay entes ya que el Ser pensado desde los entes acaba en nada, en nada de entes? El manzano en flor, la autopista o la ONU constituyen presencias, entes, cosas. El Ser no se presenta jamás ¿acaso será sencillamente nada? Pero Heidegger se 
cuestiona sobre el origen del no y de la negación en Was ist Metaphysik? - según indicación anterior - planteando el tema de la Nada: “ ¿Hay Nada porque contamos con no y negación o, tal vez, no y negación se sostienen porque previamente hay Nada?" (Heidegger, 1929, p. 7).

Heidegger se inclina por la segunda alternativa; la Nada es originariamente anterior al no y a la negación. En el mismo libro: "La Nada no se limita a ser el concepto antitético de ente, sino que la esencia del Ser mismo comporta, desde el comienzo, la Nada" (Heidegger, 1929, p. 17).

Tal planteamiento da cuenta de por qué Heidegger hace una sola cuestión de los temas del Ser y del tiempo. ¿Cómo referirse al Ser si éste no configura ente alguno? Entre la multitud de los entes destaca uno, por el hecho de preguntar, que es la existencia humana, el Dasein, término que puede traducirse, como hice antes, por el "Ahí-del-Ser". Lo expresa de la siguiente guisa, Heidegger, en Sein und Zeit - téngase presente lo indicado antes:

¿En qué ente debe leerse el sentido del Ser? ¿De qué ente debe tomar su punto de partida el proceso que nos abra al ser...?

Tal ente es el ente que somos, en cada caso, nosotros mismos y que tiene, entre otros rasgos, la posibilidad de quedar implicado en el preguntar. Lo designamos con el término Dasein (Heidegger, 1963, p. 7).

El vocablo Dasein en la filosofía alemana ha traducido la palabra latina existentia; ahora bien, en Heidegger señala al ser humano, no en cuanto sujeto, sino como punto "histórico-temporal" de la revelación del Ser. El Dasein, el ser humano, se define a modo de posibilidad, se define por existir inexorablemente fuera de sí, arrojado hacia delante. La patata, en cambio, como igualmente la sinfonía Nuevo Mundo de Dvorak, como el resto de entes, se limitan a ser en ellos mismos, desnudos de proyectos; son pastosos e inertes. La existencia humana, por el contrario, descansa sobre el ahi - del "Ahí-del-Ser" - que ella tiene, precisamente, que ser, que construir. El Dasein avanza estremecido porque se da cuenta de que no es una cosa dada, un objeto, un hecho o fenómeno, sino que nunca queda terminado aguardando su destino desde el futuro. El hombre es 
quehacer, tarea y faena, no un dato para científicos y tecnólogos; esto también lo es, claro está, pero no le especifica. Esto lo tiene en común con los mulos, con los rayos Röntgen o X, con el Principio de Arquímedes o con el correo basura. En Carta sobre el humanismo - Brief über den Humanismus - lo expresa del modo siguiente:

El Ser no es Dios. Tampoco es fundamento del mundo. El Ser está más allá de todo ente, pero se halla a la vez más cercano al Dasein que no importa qué ente, trátese de una piedra, de un animal, de una obra de arte, de un ángel o de Dios. El Ser es lo más cercano. Pero lo más cercano es para el ser humano lo más alejado. El hombre se atiene primeramente, siempre y únicamente a los entes. Pero cuando el pensar representa al ente en cuanto ente, entonces se relaciona con el Ser (Heidegger, 1947, p. 22).

El cuestionamiento salta desafiador en Was ist Metaphysik? formulado así: A fin de cuentas ¿por qué hay entes en vez de simplemente Nada? (Heidegger, 1929, p. 16).

¿Cuál es el papel del Dasein ante provocación tan hiriente? El Dasein funda la respuesta en la medida en que está comprometido con la nada. La contestación es, pues, el abismo de aquello que carece de fondo. El Dasein funda señalando el precipicio en que consiste cualquier fundamento que pretenda ser absoluto. Existir para el Dasein es diferente de existir como lo dado efectivamente. Existir para el Dasein es existirme, es conducir la propia vida, es ser accesible para uno mismo. El Dasein se apercibe de que está abí y merced a esto queda abierto a la temporalidad, a los ek-stasis, al cuidado, a la angustia, a la muerte, a la finitud. El Dasein no se halla incrustado en el tiempo; éste, el tiempo, es la manera como el Dasein es. El Dasein únicamente puede comprenderse como mortal, como anticipando su muerte. Esta no proviene del exterior, sino que constituye a la misma existencia humana. Caminando hacia la muerte es como el Dasein se da, a él mismo, su tiempo. Heidegger no considera el tiempo desde la eternidad - la cual le inyectaría sentido - sino desde el mismo tiempo. Al Ser lo comprende el Dasein a partir de la temporalidad; el tiempo encierra 
el horizonte de toda posible comprensión del Ser. El Dasein alcanza al Ser como algo implícito; la explicitación del Ser es solamente el tiempo.

Lo propio del ser humano es "no estar en su casa" - Un-zuhause -, es vivir en la "extranjería" o "inquietud" - Unbeimlichkeit; el hombre reside en el mundo pero como extranjero, como extraño. La existencia humana, que revela al Ser, está "arrojada" - Geworfenheit - al mundo y sólo le es posible proseguir a modo de "proyecto" - Entwurf. En esto consiste la temporalidad o mejor "historialidadad" - Zeitlichkeit y no Temporalität - del Dasein. Historial no es aquello que se encuentra en la historia, sino aquello que abre una historia. El Dasein posee carácter ek-stático, existiendo indefectiblemente fuera de sí. El Dasein se encuentra en el mundo - presente - pero habiendo sido arrojado en él - pretérito y en vistas al porvenir - futuro -, que no es otro que la muerte y la extinción. La temporalidad de la existencia humana es extática, lanzada hacia delante; no, así, la existencia de las pulgas o la existencia de la película Fresas salvajes de Ingmar Bergman, depositada en una filmoteca. El "ser del ahí" consiste asimismo en ser de allá. El mundo del Dasein no suma un paquete de datos; se trata de un mundo cuyo sino es "dar mundo": Die Welt weltet - "el mundo mundanizase". Ni el mundo de la merluza ni tampoco el del chimpancé ponen mundos; se ciñen a estar aburrida y obstinadamente en el suyo. El mundo del Dasein es la estructura relacional del Sein-in-der-Welt, "ser-en-el-mundo", es la "mundaneidad" - Weltichkeit.

La temporalidad que es el Dasein se traduce en Sorge - cura en latín -, “cuidado y preocupación", por cuanto le convierte en "proyecto-arrojado". Hacia delante de sí mismo; no hacia delante de algún ente mundanal. Esta huida constitutiva origina la "angustia" - Angst y no Furcht, "miedo". La angustia de ser hombre nace de la temporalidad extática. Angustiados por nada concreto y por todo a la vez. En la angustia el Dasein experimenta lo inquietante del mundo y la propia libertad. El escarabajo pelotero siempre sabe qué hacer; ni el mundo le desazona ni menos la libertad que no posee. La temporalidad constituyente del Dasein convierte a éste en Sein-zum-Tode - "Ser-a-la-muerte". El Dasein únicamente se da entre nacimiento y óbito. Heidegger no considera la muerte como algo sobre lo que triunfar - dominando el genoma humano, por ejemplo, o bien 
pensando cielos e infiernos para el post mortem -, sino que, según él, el factum de la muerte consiste en reconocer que el presente es, y sólo es, un "haber-sido". El "Ser-a-la-muerte" especifica al ser humano las moscas mueren, claro, incluida la Drosophila Melanogaster, pero éstas no se definen por la muerte -; la relación con el óbito resulta tan esencial para el hombre que, en él, el caminar hacia la muerte objetiva su poder-ser. Mientras el Dasein existe, éste resulta incompleto ya que se encuentra siempre a la espera de algo, del fallecimiento. Y cuando ya nada queda por esperar, entonces ha desaparecido el Dasein. Existir en vistas al futuro es, ni más ni menos, existir para la muerte. Esta es la última posibilidad humana, aquella que le deja perfecto - per-factum o per-fectum, completamente hecho; de facere, "hacer", y de per, "del todo".

No se cuenta con verdades absolutas a pesar de que el ser humano esté hecho para la verdad. Aletheia significó en Grecia "desocultar"; el Dasein desvela o desoculta sin parar, aunque, esto sí, desprovisto de criterio metahistórico de verdad. La verdad acaba en acontecer histórico, en proyectar sin desmayo. No contamos con otro fundamento, por tanto, que la libertad finita y acotada del hombre; el Grund - "fundamento" - acaba de tal guisa en Abgrund - "abismo y fosa". ¿Qué se esconde detrás del tiempo? Nada. ¿Cuál es el sentido de la existencia humana? El tiempo. ¿Y cuál es el sentido del tiempo? Éste carece de dirección, de rumbo y de sentido. Es dardo que juega; nada más.

En tal tesitura sólo resta caminar - Feldweg, "camino rural", y Holzweg, "camino forestal" - sin contar con rutas. Se trata de caminos, los caminos humanos, que no unen dos puntos, sino que vagabundean abriéndose paso hacia ninguna parte. Únicamente se dispone de sendas, sin meta, caminos sin mayor importancia que se abren al andar. La existencia del hombre es un espacio de juego, es actividad lúdica, es pasatiempo.

\section{Heidegger y el repto al humanismo occidental}

Angustiados como estamos en el comienzo del siglo XXI por los valores morales, cabe interrogarse sobre la ética en Heidegger. ¿Qué dice, éste, de 
la orientación ética? ¿En qué acaba la moral en manos de este considerable postmoderno? Desde luego no contamos con moral si con tal significante entendemos un cuerpo de principios y de fines que iluminan con autoridad a la conducta. Con todo, la Kehre - "viraje decisivo" - heideggeriana, consistente en el paso de la ontología a la ontología, pone el acento en la motivación ética. Tres son sus obras en que tal subrayado resalta: Brief über den Humanismus, Sein und Zeit y Kant und das Problem der Metaphysik. El hombre, su humanitas, consiste en conducirse, en situarse. Y es cuestión de una conducta que pone en juego al Ser. El Dasein al conducirse abre el espacio del sentido. Hay que inyectarle sentido al hecho de ser. El Dasein no es más que eso: trabajo para proporcionar sentido. El hecho de estar siendo es, ipso facto, poder y amor del sentido. $\mathrm{Y}$ ¿en qué se manifiesta dicho sentido? En llevar la verdad del ser hasta el lenguaje.

La humanitas del Dasein se concreta en el actuarse mismo de éste, entendido, dicho actuarse, como paradigma absoluto. Carece de sentido arrancar de interpretaciones previas, ya dadas, como el cristianismo o bien el marxismo. El Dasein, siendo finitud, reconoce en el inacabamiento el requisito de su realización como sentido. La meta del ser no es dato alguno; es tarea y vagabundeo. Ningún valor ni ideal alguno señalan el ritmo a la existencia concreta. Nada precede a la existencia extática del ser humano. El ahí, del "ser-ahí" - Dasein -, queda siempre abierto en el laboreo de proporcionarse significado; el Ser consiste esencialmente en hacerse sentido. ¿Cuál? Cualquiera. Es una ética, ésta de Heidegger, de la indiferencia ante lo concreto, pero es una ética originaria ya que consiste en tener que darse sentido y significación antes de cualquier fijación histórica. El ser humano no es hijo de Dios, ni tampoco finalidad de la naturaleza, ni tan siquiera sujeto de la historia. ¿Qué es, pues? El existente donde el Ser se "ex-pone" como produciendo el sentido, excediendo siempre cualquier sentido fáctico o bien ideal. La "ek-sistencia" - el "salir inexorablemente de sí mismo" - es el sentido; ella, la "ek-sistencia", no tiene sentido, carece de meta y de culminación. No contamos con otra cosa como no sea el tránsito y la carrera, los cuales únicamente concluyen en el finamiento y la expiración. 
Si se acepta el análisis heideggeriano se comprende óptimamente la platitud o trivialidad de los valores que se divierten de manera juguetona en la actividad educativa postmoderna. Heidegger ha proporcionado coherencia a la postmodernidad; lo estúpido está en vivir en el seno de ésta de manera inconexa, contradictoria.

¿Resulta posible superar el planteamiento heideggeriano, el tanteo postmoderno? La negativa abandona a los procesos educativos en la estupefacción. O ilógica o suicidio. ¿Inactividad? A ésta la asegura el suicidio. Las llamadas pedagogías líquidas son diversiones lúdicas o bien incoherencias; como pasatiempos académicos resultan más o menos juerguistas, chistosos. No dan más de sí. Leído y meditado Heidegger, o suicidio educacional o bien insensatez y despropósito en la tarea educativa. La an-arkhé, "el sin-principio", la negación de lo primero y del factor ordenador vive solamente sobre el papel. Ni la historia ni las sociedades lo soportan.

En el contexto del ya fenecido siglo xx tan abigarrado y desconcertante ¿cómo descubrir nuestros valores occidentales a fin de iniciar la caminata del xxI? Estimo que la tradición que nos tiene vertebrados permite orientarnos dando sentido a la continuación del existir histórico. Ciertamente, los elementos postmodernos resultan difíciles de casar con la tradición, pero tampoco parece un quehacer del todo imposible. Reliquias y nostalgias, en cambio, facilitan la tarea porque siguen viviendo desde el sentido que Occidente ha ido inyectándose a lo largo de la peripecia temporal.

Ha quedado destruido el modelo humanista de la Cristiandad - siglos $\mathrm{X}-\mathrm{XV}$ - medieval, pero sobrevive, en el plano del discurso cuando menos, la categoría encarnación. Esta enfrenta y a la vez asume al profetismo judío y a la racionalidad griega atada a la tecnología romana. Conflictos y encuentros se suceden entre ambos elementos. Fe - apuesta y valores cara a cara con la Razón - determinismo y técnicas. El profetismo hebreo se objetivará históricamente en liberté, égalité, fraternité; el tecnocientismo grecorromano proporcionará ciencias tanto axiomáticas como empíricas y así mismo tecnologías de toda suerte.

Mi enfoque se sitúa aparte, a mitad de camino entre lo simplemente dado y lo ontológicamente obligante; la historia regional de Occidente indagando experiencialmente su legitimación o sentido es más que un 
dato bruto y menos que una obligación radicalmente fundada. Las valoraciones son hechos históricos; los valores, por el contrario, de existir, se refieren a algo metahistórico. Sin embargo ¿no podemos imaginar que las valoraciones fabricadas por Occidente disfruten de mayor consistencia que la simple facticidad? estar persiguiendo comunitariamente el sentido del ánthropos es superior que simplemente pasar por el decurso temporal como haría la res de un rebaño. Gadamer dice en Verdad y método:

Para toda praxis humana hay algo que está ya decidido, y es que tanto el individuo como la sociedad se hallan orientados hacia la felicidad (Gadamer, 1984, p. 662).

Correr tras la felicidad no se hace mecánicamente, sino con diálogo y de manera razonable. Los valores creados no se reducen a superestructuras de la lucha de clases; contamos además con el trabajo de tener que precisar el telos. La insatisfacción de la existencia - con su cinismo o bien desesperación al acecho - pide la esperanza en la utopía antropológica. El mundo se presenta, al cuerpo humano, de forma significativa y no como zoológicas sensación y percepción, cosa propia del mosquito o del paquidermo. No es el cuerpo el que percibe, sino yo y éste cuenta con la libertad cuando hay conciencia de futuro; de no haberla, la conducta es la de una acémila aunque con bioquímica cerebral más compleja.

Las finalidades antropológicas se producen históricamente en la interrelación humana. Alfred Schütz (1932) hace notar que el núcleo del mundo social se encuentra en el cara a cara, de uno frente a otro, en el interior de un tiempo y de un espacio precisos. No es posible la "autocomprensión" - Selbstversteben - sin la "heterocomprensión" - Fremdversteben. Filosofar en torno a los valores será irremediablemente "co-filosofar", symphilosophein, y aquí radica el peso de los valores históricos, aquellos que nos entrega la tradición; son valores de una "comunidad" - Gemeinschaft y no de una "asociación" - Gesellschaft.

Históricamente hemos vivido Leben im Aufschub, hemos "vivido en constante prórroga" y demora como si no acabara de llegar lo más interesante. El "ahora” intenso - bo nun Kairos - no se ha presentado todavía. 
En tal espacio temporal expectante Europa elaboró sus valoraciones-valores, y las ha producido el uno para el otro, y no de forma egoísta según prescribe el modelo cartesiano del ego cogito. Los sujetos históricos en comunidad han querido establecer un orden sensato en contra de las matanzas, las cuales olvidan que el otro es igualmente sujeto. El discurso se ha mostrado más magnánimo que la desnudez de los hechos. Pero los valores no son hechos sino cabalmente discursos. De espaldas a la intersubjetividad el sujeto acaba siendo pérfido. Un sujeto absoluto deja de ser persona; los valores de Europa los han animado el diálogo y la discusión y no la omnisciencia de déspotas inspirados, trátese de políticos, de eclesiásticos o de tecnocientíficos. Los estructuralistas y luego Foucault (1969) y Deleuze (1968) han olvidado al sujeto, pero ¿no se trata, tal vez, del sujeto de Descartes en vez de referirse al sujeto paciente de Levinas que se construye precisamente desde la importancia del tú? El sujeto autónomo no ha predicado los valores de Occidente; sí, en cambio, lo ha hecho el yo solidario o que se esfuerza por serlo.

No queda tratada la cuestión de los fundamentos de la axiología, sino que abordo tan sólo el tema de los contenidos o valores, particularmente de aquellos que estimo matrices. En todo caso no me refiero a fundamentos ontológicos del humanismo occidental. Lo que sí ha quedado sentado, en cuanto a "fundamentación" - Grund o arkhé -, es que la hermenéutica practicada legitima con la phrónesis - "prudencia" - los contenidos axiológicos que presento. La Selbstreflexion, "auto-reflexión”, la he llevado a cabo desde la tradición europea, a mitad de camino, pues, entre una lectura emancipadora - Habermas - y una lectura rememorante - Gadamer. Ignoro si contaremos con una escatología de la liberación, muy habermasiana pero igualmente muy judía; lo indiscutible es la luz de la tradición.

El hombre se define por la capacidad de hablar y esta capacidad vive particularmente de cuestionar, argüir, objetar, inquirir, pedir cuentas, indagar. Quien habla, pues, se inscribe en el futuro reconociéndose como proyecto: ¿qué va a ser de mí? Instalarse exclusivamente en el instante abre a la deshumanización. Alfred Schütz (1923) encuentra el fundamento de las ciencias sociales, no en constructos social-científicos, sino en el sentido social de cualquier actuación. El ser humano es caminante que va 
tras el sentido. ¿Vale la pena proseguir? Abraham responde que sí, y así se sigue hasta la Ilustración y el marxismo y el mismo positivismo - cuando menos el de Comte. Lo nuestro es la Pascua, el Pessah judío, el pasar por encima de; es decir, el continuar superándonos. Igual adviene el Machyah, el Mesías, lo esperado. Si el mundo fuera absurdo, la moral estaba de más. Pero ¿puede no ser absurdo si no disponemos de Absoluto - perspectiva postmoderna - aunque se trate del de la Modernidad? ¿Con la nausée sartriana, postmoderna - Sartre fue lógico; no así otros postmodernos -, no hay modo de levantar una ética y sin ésta el humanismo que pudiera nacer sería tan efímero que resultaría preferible embriagarse y aturdirse. Si pretendemos hacer únicamente un mundo rico, lo fabricamos postmoderno, enajenado y bebido.

El humanismo occidental no puede existir en la "subida" o anábasis y en la introspección sempiternas; su destino es la apertura, llevando la encarnación cristiana - lo judío dentro de lo griego y de lo romano -, que ha embebido a la Modernidad entera y sobrevive a modo de reliquia y de nostalgia en la Postmodernidad, transfiriendo, decía, la encarnación a otros pueblos y civilizaciones, aunque, esto sí, a manera sólo de propuesta y ofrecimiento. No contamos con Verdad en contra de lo que sostienen el Papa de Roma y Bin Laden. La neurosis no es la Verdad. La Verdad es cosa únicamente del Eterno y éste se nos muestra como silencio.

Se invita a la educación moral. ¿Cómo fundarla si previamente no se ha proporcionado el sostén de la moral? Cada época ha engendrado su axiología y ha pedido que se tenga el coraje de abrazarla. La pregunta, entonces, salta así: ¿basta con transmitir la herencia moral que hemos recibido? Este interrogante remite a qué modelo antropológico débese aceptar. ¿Qué ser humano pretendemos formar con la educación? indiscutiblemente el de mañana; al fin y al cabo educamos principalmente a infantes, púberes y adolescentes, y no a adultos. La voluntad educadora es voluntad de futuro. ¿Qué humanidad queremos para el día de mañana, para el día de después? Mi investigación entera ha procurado responder a tan apremiante cuestión. Como afirma Gadamers (1984) antes de ser nosotros somos historia; no resulta factible apuntar en Occidente hacia el porvenir si ignoramos cómo se ha sedimentado en Europa un modelo 
de hombre que insiste en continuar. El futuro sería una fofa fantasía, planteado desde el presente, a no ser que se arranque de lo que Europa ha pensado antes con obstinación una vez se ha liberado de la ganga histórica.

Nuestros antepasados, desde Jerusalén, Atenas y Roma, han hablado entre ellos - pragmática lingüística -, juntos unos con otros frente a otros y con el dolor, la alegría y la perplejidad en el corazón. El lenguaje fue y ha sido Gespräch - "diálogo" -, camino hacia el entendimiento de todos. Este, y no otro, constituye el último sentido de la comunicación. El habla, además de juicio y razonamiento, es pregunta y respuesta. Hablamos no sólo para comunicarnos las bagatelas cotidianas, mas igualmente con ánimo de dirigirnos hacia algo que podamos tener en común. Hablando entre sí las féminas y los varones del área europea han ido construyendo a lo largo de la historia un Weltall, un universum, un kosmos, precisamente el llamado occidental. El mundo no es adición de átomos, de neuroconductores..., el mundo que nos agobia y desasosiega es destacadamente Menschenwelt - el "mundo del ser humano". El mundo es el mundo del hombre, mundo que deviene, que acontece, y que jamás queda concluido. El mundo para nosotros es el de Occidente, elaborado con sangre y sollozos y con algún que otro menudo gozo. A partir de aquí puede pensarse una moral cara a lo venidero, una moral para el rejuvenecimiento.

Nuestra tradición ha forjado derechos humanos con el paso del tiempo. Derecho del inculto a la cultura, sea cuestión de un párvulo o bien de un analfabeto. Cultura del cuerpo, de la razón, del espíritu o penetración en lo esencial, del alma o capacidad de buscar el porvenir total, del corazón o sentido de la bondad. Cada quien es persona; esto quiere decir que no puede someterse a nadie a un juicio absoluto.

\section{Conclusión}

Europa arrancó del judaísmo - siglo XI a.C. - y desde éste a través del paganismo grecorromano, finalmente helenismo - desde el siglo III a.C. -, dio paso al cristianismo - de forma clara después de 325, primer 
Concilio de Nicea. El Islam - inicios del siglo VII - proviene también de la Weltlanschauung o cosmovisión hebrea pero no ha transitado todavía - quizás no lo haga nunca, quizás no pueda hacerlo - por la Modernidad mientras que el cristianismo ha sufrido la noche de la Ilustración sin haberla superado, sin embargo, con éxito. Semitismo - ámbito judío e islámico y cristianismo carecen de palabras con las que dialogar. Se trata, según estimo, de quien vence sobre quien. Y que Dios nos coja tranquilos. Igual, empero, lo que parece imposible acaba realizándose.

Está a nuestro alcance burlarnos de los valores que la tradición nos ha legado, pero ¿resulta prudente perecer como idiotas por no tener el coraje de hacerle frente al poder demente?

El humanismo del siglo XXI no brotará así, de improviso e inesperadamente, sino que se alimentará de su tradición. Europa, Occidente, configura una historia. La comprensión de sí mismo se obtiene a través de la comprensión de la historia de los símbolos culturales, en los cuales y desde los cuales adquirimos forma y consistencia. En Husserl (1977) leemos: "Le plus grand péril qui menace l'Europe, c'est la lassitude." El riesgo europeo reside en el cansancio, en el fastidio y tal vez incluso en el asco. Sin esperanza desfallecen los valores y las tareas. ¿Por qué no volver la mirada hacia el a priori cristiano? Quizás cobren, de tal guisa, vigor y lozanía nuestras alas de futuro y de posteridad, siempre, claro está, que se trate del cristianismo primigenio y no del prostituido con los siglos.

\section{Bibliografia}

Deleuze, G. (1962). Nietzsche et la philosophie. Paris: Puf.

Deleuze, G. (1968). Différence et répétition. Paris: Puf.

Farias, V. (1989). Heidegger y el nazismo. Barcelona: Muchnik, D.L.

Fermoso, A. J. (1982). Teoría de la educación. Barcelona: CEAC.

Foucault, M. (1969). L'archéologie du savoir. Paris: Gallimard.

Gadamer, H. (1984). Verdad y método. Salamanca: Sígueme.

Heidegger, M. (1927). Grundprobleme der phänomenologie. Frankfurt: Vittorio Klostermann. Heidegger, M. (1927/1963). Sein und zeit. Tübingen: Niemeyer.

Heidegger, M. (1929). Was ist metaphysik. Bonn: Friedrich Cohen.

Heidegger, M. (1947). Brief über den bumanismus. Bern: Francke Verlag. 
Heidegger, M. (1953). Einfübrung in die metaphysik. Tübingen: Niemeyer.

Heidegger, M. (1957). Der satz vom grund. Pfullinger: Neske.

Heidegger, M. (1961). Nietzsche. Pfullingen: Neske.

Heidegger, M. (1965). Kant und das problem der metaphysik. Franfurt a.M.: V. Klostermann.

Heidegger, M. (1969). Zur sache des denkens. Tübingen: Niemeyer. Frankfurt a.M.: V. Klostermann.

Husserl, E. (1977). La crise de l'immensité européenne et la philosophie. Paris: Aubier.

Jaspers, K. (1978). Notizien zu Martin Heideggers. München-Zürich: Piper.

Luhmann, N. (1993). El sistema educativo. Mexico: Universidad de Guadalajara/ Universidad Iberoamericana/ ITESO.

Palmier, J.-M. (1968). Écrits politiques de Heidegger. Paris: L'Herne.

Rorty, R. (1979). Philosophy and the mirror of Nature. Cambridge: Cambridge University Press.

Rorty, R. (1989). Contingency, irony and solidarity. Cambridge: Cambridge University Press.

Schütz, A. (1932). Der sinnhafte aufbau der sozialen welt. Viena: Springer.

Wiggins (1991). Needs, values, truth. Oxford: Basil Blackwell. 